\title{
Nanotoxicology and Exposure in the Occupational Setting
}

\author{
Tiago Severo Peixe ${ }^{1 *}$, Elizabeth de Souza Nascimento², Katie Larson Schofield ${ }^{3}$, \\ Arline S. A. Arcuri ${ }^{4}$, Rachel P. Bulcão 5 \\ ${ }^{1}$ Departamento de Patologia, Análises Clínicas e Toxicológicas, Universidade Estadual de Londrina (UEL), \\ Londrina, Brasil \\ ${ }^{2}$ Departamento de Análises Clínicas e Toxicológicas, Faculdade de Ciências Farmacêuticas (FCF), Universidade \\ de São Paulo (USP), São Paulo, Brasil \\ ${ }^{3}$ The Work Comp Experts (SFM), Minneapolis, USA \\ ${ }^{4}$ Coordenação de Higiene Ocupacional, Fundacentro, Ministério do Trabalho e Emprego, São Paulo, Brasil \\ ${ }^{5}$ Faculdade Educacional Araucária (FACEAR), Araucária, Brasil \\ Email: tiago@uel.br
}

Received 8 June 2015; accepted 27 July 2015; published 30 July 2015

Copyright (C) 2015 by authors and Scientific Research Publishing Inc.

This work is licensed under the Creative Commons Attribution International License (CC BY). http://creativecommons.org/licenses/by/4.0/

(c) (i) Open Access

\begin{abstract}
Nanotechnology refers to the ability to control the composition of molecules and atoms within the range of $1.00-100 \mathrm{~nm}$. At this scale, many materials exhibit novel properties when compared with their micro or macro-sized equivalents, including, for example, chemical reactivity, strength, mobility and solubility. Nanoparticles are prime candidates for toxicity because they possess a much greater surface to volume ratio (i.e. the surface area compared to the volume) than larger particles of that same material; they can have biopersistance and higher oxidant capacity, penetrate epithelium and reach interstitial pulmonary region. In an industrial setting, workers may present the main exposure risk potential among humans, and they may be involved in the entire product life cycle. There are needs to protect public and environmental health and safety. Currently, no standards or regulations exist that apply or refer specifically to nanomaterials impacts.
\end{abstract}

\section{Keywords}

Nanotoxicology, Occupational, Workers, Nanoparticles, Exposure

\section{Introduction}

Conceptually, nanotechnology is the understanding and control of matter at dimensions between approximately "Corresponding author.

How to cite this paper: Peixe, T.S., de Souza Nascimento, E., Schofield, K.L., Arcurid, A.S.A. and Bulcão, R.P. (2015) Nanotoxicology and Exposure in the Occupational Setting. Occupational Diseases and Environmental Medicine, 3, 35-48. 
1 and 100 nanometers, where unique phenomena enable novel applications. Encompassing nanoscale science, engineering, and technology, nanotechnology involves imaging, measuring, modeling, and manipulating matter at this length scale. A nanometer is one billionth of a meter. A sheet of paper is about 100,000 nanometers thick; a single gold atom is about a third of a nanometer in diameter. Dimensions between approximately 1 and 999 nanometers are known as the nanoscale. Unusual physical, chemical, and biological properties can emerge in materials at the nanoscale. These properties may differ in important ways from the properties of bulk materials and single atoms or molecules [1] [2].

It is within this range that materials can have substantially different properties compared to the same substances at larger sizes, both because of the substantially increased ratio of surface area to mass, and also because quantum effects begin to play a role at these dimensions, leading to significant changes in several types of physical properties [3].

In the nanometer scale, materials have their morphology and surface modified. New technological properties are achieved. The large surface-area to volume ratio leads to significantly increased chemical reactivity. Quantum effects emerge, leading to unusual electronic, optical, magnetic and other phenomena [4]. Properties like chemical reactivity, strength, mobility and solubility are different from large scale. The nanoscale is almost incomprehensible, with the width of a strand of DNA, estimated to be $2 \mathrm{~nm}$, while the width of a red blood cell is estimated to be $7000 \mathrm{~nm}$ (or $7 \mu \mathrm{m})[5]$.

The magnitude of investment in nanotechnology R \& D (Research and Development) is in stark contrast to the scale of the technology itself, with global investment in 2008 alone estimated to be US\$ 30 billion. Some estimate that nanotechnology promises to far exceed the impact of the Industrial Revolution and is projected to become a US\$ 4.4 trillion market by 2018 [6] [7].

But despite this growing investment, a relatively little amount is spent on the research on the potential risks associated with these new technologies. In the USA, The National Nanotechnology Initiative (NNI) coordinates Federal R \& D activities related to nanotechnology. 5\% of the total NNI budget is dedicated to Environmental Health and Safety (EHS), and then $95 \%$ of the budget is dedicated to non-EHS research. This imbalance translates to actual research, development, testing, and evaluation imbalances, i.e., there are far more research publications and grants concerning fundamental nanotechnology R \& D than concerning toxicology, exposure assessment, morbidity, and mortality [8].

So, the rapid growth of the nanotechnology and nanomaterial field has been influenced by the huge promises of technological and financial gain. Although the promises are numerous, the risks and problems associated with the wide-scale production and use of nanomaterials have not been fully explored or documented. The largest risks from nanomaterial exposure result from the unique and unpredictable characteristics of materials at the nanoscale [9].

This paper explores the toxicological effects of nanomaterials on the body through an assessment of known data on the various exposure routes for nanomaterials to enter the body, the effects of the particles on the biological tissues, and the possible systemic translocation, biopersistance in the body, and acute and chronic health effects produced. Additionally, the paper explores the exposure of the worker to nanomaterials in an occupational setting from particle release, and the controls and methods, both in place and needed to keep employees safe from harmful and long term health effects.

\section{Toxicological Assessment}

Biological effects caused by nanoparticles deposition are related to their physical and chemical parameters. These effects do not just depend on the intrinsic toxicity of the material. The chemical characteristic, size, and surface property of nanoparticles (NP) influence on toxicity. The chemical make-up, size and surface properties of nanoparticles may play a more significant role than mass alone in determining systemic distribution and toxicity [10]-[15]. The surface and chemical properties of particles play a large role in influencing movement, adhesion, and modulation of physiological pathways [12] [16] [17].

An important need to be understood is that of the variety of synthesis techniques which can produce nanomaterials with different physical characteristics, such as size, morphology, surface chemistry, and biological coatings, which results in different biological effects. Pre-analytical errors could originate during the manufacturing stage and researchers should not solely rely on data from the production industry or assume that nanometer (NM) remains unchanged throughout the duration of experiments. Additional variations in NM properties from differ- 
ent batches or sources can lead to erroneous results. For example, if two nanosized powders (e.g., silver and carbon) are produced by two companies employing different synthesis techniques, the following questions arise: are the powders similar enough to be considered the same? If not, which characteristics are similar, which characteristics vary from each other, and what accounts for these differences? An additional point to consider is whether or not the NM sizes can be manufactured with a uniform or narrow size distribution. These factors complicate the comparison of NM from different companies, thus limiting the supply of characterized materials to one or a few manufacturers, and make it very difficult to compare lab-to-lab biological effects.

The issues reveal the need to establish comprehensive characterization of the NM being examined in nanotoxicity studies. Additionally, standard reference materials (SRMs) need to be defined to aid in NM characterization and allow an accurate lab-to-lab comparison. Moreover, the dynamic nature of NMs in biological systems is of particular importance as their properties may change depending on the environment (e.g., the $\mathrm{pH}$ ), transport, and mechanisms of accumulation, degradation, and release [18].

The chemical make-up of nanoparticles often contains a number of impurities or soluble metals that cause free radical production and inflammatory responses [11] [19]-[21]. Particles with an acidic nature may be more harmful due to a number of electrostatic interactions and optimally enhanced uptake into cells [14] [16]-[18].

These problems allow us to understand the difficulties to know the toxicological properties of NM. These specific characteristics of NM toxicology lead to an emerging discipline-Nanotoxicology-that can be defined as "the science of engineered nanodevices and nanostructures that deals with their effects in living organisms". Nanotoxicology research not only will provide data for safety evaluation of engineered nanostructures and devices but also will help to advance the field of nanomedicine by providing information about their undesirable properties and means to avoid them [22].

It remains uncertain to what extent toxicological properties are also changed. From a toxicological point of view nanomaterials of poor solubility in biological fluids are of special importance, because they maintain their nanostructure after contact with the human body. The most important nanomaterials are at present nano-objects like nanoparticles, nanotubes, nanorods or nanoplates, including their aggregates and agglomerates that are "available" for skin contact or inhalation [23]-[25].

In agreement with BSI Vocabulary-Nanoparticles, nanoparticle is a particle with one or more dimensions at the nanoscale. So, this is the vocabulary used in this paper. Nanoparticles (NP), due to their small size and corresponding large specific surface area, have specific properties that make them desirable as catalysts for chemical reactions. Increased surface reactivity predicts that NPs exhibit greater biological activity per given mass compared with larger particles [26] [27].

Many studies have been conducted to try to determine the effects and understand the mechanisms in which NPs or ultra-fine particles can cause damage to the body. An important point in assessing the risk and effects of nanomaterials is their penetration into the body. The three main primary routes by which NM may enter-the human body from the outside environment are inhalation, skin exposure and ingestion, where the toxicity targets are the respiratory, intergumentary and gastrointestinal systems, respectively [28]. The pulmonary route is the main route of concern. The particles can enter the body, the smaller they are, the deeper into the lung tissue they can go [21], and from there enter the blood stream. Also, the effects of nanoparticles on the respiratory and cardiac system seem to be more severe than on other systemic targets [29]. As with many harmful substances, the people at greatest risk to experience adverse health effects from exposure to nanoparticles include those with chronic pulmonary obstructive diseases, cardiac diseases, asthma, and the elderly [11] [12].

Women are slightly more susceptible to exposure due to smaller size of airways-breathing patterns representing people's conditions/activities [30]. Exposure to pollution for as little as two hours increased the occurrence of myocardial infection in people at risk of cardiovascular problems [21].

In a recent study, Shin et al. (2015) conducted an experiment within rats were exposed to graphene in two levels, during $5 \mathrm{~h} /$ day, and for a 28 day period, evaluating macrophage ingestion and bioaccumulation, in this experiment, the nanocompound suggested a minimal toxic effect, regarding the inhalatory toxicology [31].

\subsection{Effect of Nanoparticles on Pulmonary System}

Epidemiological studies into incidental (unintentional) NP are beginning to demonstrate there are some serious health effects associated with chronic exposure. Workers with prolonged exposure periods to NP form combustion engines or welding fumes have higher incidences of lung cancer, chronic obstructive pulmonary disease, fi- 
broids and cardiovascular diseases [28].

Researchers have proven that NP can be deposited in the lungs, and depending on a number of variables, may make their way into the circulatory system. In a study by Takenaka et al. (2004) low doses of nanoparticles were retained in the lungs, with very little systemic translocation. However, higher doses resulted in lung injury and systemic translocation, including translocation to the liver and kidneys. Nanoparticles have a high diffusivity and are deposited in lung meaning by diffusion when inhaled. Deposition is greater with smaller sized particles at a slow breathing rate, and as the radius of the airway decreases deeper in the lung, deposition increases [5] [25] [30]. Each region of the respiratory system is targeted differently by different sizes of particles. Particles with 1 $\mathrm{nm}$ in size have a $90 \%$ deposition in the nasopharyngeal region, only $10 \%$ in tracheobronchial, and none in alveolar region. Changing the particle size slightly will dramatically change deposition. Particles with $5-10 \mathrm{~nm}$ will deposit in all three regions with about $20 \%-30 \%$ efficiency, while particles with $20 \mathrm{~nm}$ in size will have a $50 \%$ deposition rate in the alveolar region. Particles will be clear by the mucosal elevator to the GI tract, or through macrophages. An overload of particles impairs microphages [11] [13] [22]. In the review of Chan-Remillard (2009) it was evidenced that persistence within the lung may increase the potential for translocation of NP to other target organs in the body. Translocation into the blood stream can occur via the air/blood barrier, through the lymphatic system, movement further into the lung tissue or interstitium or via the sensory neurons. Particles in nanoscale have been found to penetrate beyond the basement membrane into capillary lumen and then attach directly onto red blood cells. This may explain the cardiovascular consequences of exposure. Inhaled $\mathrm{NP}$ has been detected in liver and bladder, heart and spleen, lymph nodes and in the olfactory bulb and different regions of the brain after varying periods of exposure [28] [32].

Pietropaoli et al. (2004) showed that nanoparticles caused pulmonary inflammation, which enhanced ability for inflammatory response. This caused mild airway obstruction due to inflammation or constriction, but without the presence of oxidative species or cytokines. Yet, for those which chronic obstructive diseases or asthma, the additional inflammation or breathing burden could have major medical implications [16] [17] [33].

A number of different mechanisms are suggested about the way in which nanoparticles affect pulmonary system, and then other systems of the body, namely the cardiovascular system. The first mechanism involves the inflammatory response system of the lungs. The cells of the pulmonary system become inflamed and generate oxidative species in response to particles uptake and/or contact [16]. These reactive species will damage cellular proteins, lipids, and membranes, so that the cell needs to defend itself, and use stocks of antioxidants, which can induce a state of cellular oxidative stress. This stress triggers an increase in the production of antioxidant enzymes. If the cell fails to overcome this stress, activation of cytokine and chemokine production will occur and cause a widespread pro-inflammatory response [13] [19] [34]. Mediators are released from lung tissue into circulation and effects will reach sites remote from the initial damage [16] [20] [21]. Particle loaded macrophages may also be released into circulation due to increased permeability from inflammatory mediators [12].

For NP, two additional mechanisms can reduce the concentration of particles in the lungs. The particles can pass to the extrapulmonary organs via the bloodstream, while some particles can be transported along the sensory axons to the central nervous system (CNS). These two mechanisms appear to play a significant role in the development of cardiovascular, cardiac, or CNS diseases [18]. A translocation pathway for solid particles in the respiratory tract involving neuronal axons is apparently specific for NPs [35] [36].

Alyaudin et al. (2001) study confirmed the fact that certain nanoparticles have the ability to cross the blood brain barrier. The blood brain barrier greatly limits the entry of materials into the central nervous system and brain, as a protective measure. The protective barrier is accomplished through a number of methods, including tight intercellular junctions between the cells of the cerebral capillaries, metabolizing and detoxifying enzymes, and outwardly directed pumps. These methods prevent free diffusion of solutes, and form a physical and transport barrier into the brain. Certain nanoparticles, however, have been shown to be able to cross the blood brain barrier, initiating a process of fluid-phase endocytosis or triggering a reaction leading to their internalization. It seems that the surface properties of the particles are the key to their internalization, namely having a hydrophilic coating [37].

Another study also looked at the passage of nanoparticles through the blood brain barrier. It was found that particles may pass through less developed areas of the blood brain barrier, but more importantly, they can pass from the olfactory nerve into the brain. This is especially pertinent to very small particles $(1-5 \mathrm{~nm})$ because they are deposited with about $90 \%$ efficiency in the nasopharyngeal region. Although no absolutely conclusive information on nanotoxicity exists, there is enough suspicion of harm to warrant preventative actions [36]. 
In the lungs, when NP are translocated into the blood stream, they can cause heart rate/rhythm abnormalities, changes in blood coagulability, which promotes the formation of thromboses, directly affect the walls of the heart and blood vessels, increase platelets, and destabilize plaques, all of which increases risk of myocardial infarction in vulnerable populations and affects cardiac function [38] [39]. The platelet activation and pro-thrombosis, caused by the particles on circulation, is believed by Nemmar et al., (2002) to be caused by positive charged surface properties of certain particles. The positive charged ones cause interaction and create cross bridges with the platelets [21].

Henneberger et al. (2005) conducted a study that agreed with the mechanism of oxidative stress and inflammation causing indirect or secondary affects [20]. Harder et al. (2005) also agreed with the autonomic response theory, leading to an imbalance in sympathetic and parasympathetic cardiac autonomic function. They found no blood coagulation, or systemic effects, which support activation of neural receptors in the deep lung [38].

Preliminary information suggests that the majority of nanomaterials which are marketed in large volumes or will experience a considerable increase in nano-market share in a near future are composed, of the following basic materials: aluminum oxide; carbon: carbon black; carbon: carbon nanotubes; cerium oxide; dendrimers; fullerene; iron oxide; nanoclays; polystyrene; silicon dioxide: amorphous and crystalline; silver; titanium dioxide and zinc oxide [23] [24].

Carbon nanotubes (CNT) are one of most important NP. They are cylinders of either single-(SWCNTs) or multiwalled (MWCNTs) carbon atoms covalently bonded in a hexagonal network of dimensions approximately $1-50 \mathrm{~nm}$ (diameter) by $\leq 100 \mu \mathrm{m}$ length. The characteristic CNT structure contributes to its tremendous mechanical strength which is many times greater than steel. Furthermore, it is the combination of large surface areas, electrical conductivity and mechanical strength that holds promise for the eventual use of CNTs in composite materials or nanoscale devices. Distinctive electron transport and magnetic properties have also been observed thus providing further potential uses in nanoelectromechanical devices. CNTs can be further modified by chemical reactions (i.e. "derivatised") that alter the original properties of the otherwise mostly chemically inert CNTs [40].

A number of studies have been done specifically with carbon nanotubes, which have produced concerning results. Exposure to nanotubes produced transient lung inflammation and granulomas. It is believed that macrophages in the lung engulf the nanotubes, but then die, leaving scar tissue patches of granulomas. The mechanism of oxidant generation, cellular toxicity, antioxidant depletion, and loss of cellular activity is believed to be the cause of the macrophage death [41]-[43]. Warheit et al. (2004) also reported a study from Shvedova et al. (2003) that concluded that dermal exposure to unrefined single wall carbon nanotubes can result in oxidative stress and toxicity in the skin of exposed workers. It was the conclusion of Lam et al. (2004) that if nanotubes reach the lungs, they are much more toxic than quartz or carbon black, both of which are considered serious occupational health hazards in chronic inhalation exposures [44].

Inhaling carbon nanotubes could be as harmful as breathing in asbestos, and its use should be regulate it leads to the same cancer and breathing problems that prompted a ban on the use of asbestos as insulation in buildings. Scientists observed that long, thin carbon nanotubes look and behave like asbestos fibers, which have been shown to cause mesothelioma, a deadly cancer of the membrane lining the body's internal organs (in particular the lungs) that can take 30 to 40 years to appear following exposure. Asbestos fibers are especially harmful, because they are small enough to penetrate deep into the lungs, yet too long for the body's immune system to destroy [39].

The researchers reached their conclusions after they exposed lab mice to needle-thin nanotubes: The inside lining of the animals' body cavities became inflamed and formed lesions.

\subsection{Effects of Nanoparticles on Skin}

Oberdörster (2005) indicates that a potentially important uptake route is through dermal exposure. The dermis has a rich supply of blood and tissue macrophages, lymph vessels, dendritic cells (Langerhans, also in stratum spinosum of epidermis), and five different types of sensory nerve endings. Broken skin represents a readily available portal of entry even for larger $(0.5-7 \mu \mathrm{m})$ particles, as evidenced by reports about accumulation of large amounts of soil particles in inguinal lymph nodes of people who often run or walk barefoot; this can be associated with elephantiatic lymphedema (podoconiosis) [22]. Tinkle et al. (2003) hypothesized that unbroken skin when flexed-as in wrist movements-would make the epidermis permeable for NPs. They demonstrated in a 
proof-of-concept experiment that, indeed, flexing the skin, but not flat skin, resulted in penetration of even $1 \mu \mathrm{m}$ fluorescent beads to the dermis. The follow-up question about access of particles in the dermis to the circulation is answered by the aforementioned reports of podoconiosis, that is, uptake into the lymphatic system and regional lymph nodes. Subsequent translocation of NPs beyond lymph nodes to the blood circulation is likely to occur as well, as shown in studies with small asbestos fibers [25] [35].

Oberdörster made another question which relates the potential of sensory skin nerves with the take up and translocation of NPs. Given that this mechanism has been demonstrated for the nasal and tracheobronchial regions of the respiratory tract, how likely is this to occur in the dermis layer of the skin with its dense supply of different types of sensory nerves? It may be conceivable, considering data on neuronal uptake and translocation of NSPs after intramuscular injection [25] [35].

\subsection{Effects of Nanoparticles on Gastrointestinal Tract}

Particles deposited in the respiratory system that are cleared via the mucociliary escalator may be swallowed, leading to exposure to the GI tract. Additional ingestion routes include the use of nanostructured materials in food, water, and drugs. Relatively few studies have investigated nanostructured materials in the GI tract, and most have shown them to pass through and be eliminated rapidly [44] [45]. Like dermal exposure, oral exposure could be a significant occupational and environmental route, resulting from ingestion of contaminated food and water, the swallowing of inhaled particles, or hand-to mouth transfer of particles. While many nanoparticles have been shown to undergo limited GI absorption, mainly to lymphatic system, most studies have demonstrated low systemic exposure following oral administration. The available data suggest that the absorption of nanoparticles from the GI tract is governed by both the size and surface characteristics of the particle, with the smaller, hydrophobic, neutral particles having increased absorption [5].

\subsection{Effects of Nanoparticles on the Liver}

A study by Fernandez-Urrusuno et al. 1997, investigated the effect on liver cells when nanoparticles were used to assist in the delivery of drug therapies. The study found that uptake of the nanoparticles induced the release of oxidative species in the area in which they were taken up. Although the alteration of the antioxidant systems of these cells should be reversible, the depletion of antioxidant defenses in the first place can make cells more susceptible to cellular injury and death. Also, the systemic release of cytokines from lungs and vascular system has been shown to have effect on the liver in the form of promotion of clotting and anticoagulant enzymes in the liver [16] [17]. These finding were in accordance with those conducted by Bulcão and coworkers (2015) [46], the authors state that the depletion of antioxidants was not great enough to initiate hepatocyte damage, since no changes in lipid peroxidation and reversible alterations were observed. Bulcão et al. (2013, 2014) [47] [48] demonstrated that liver parameters including serum levels of albumine (ALB), total protein, alkaline phosphatase (ALP), alanine aminotransferase (ALT), aspartate aminotransferase (AST), and lactate dehydrogenase (LDH) were not significantly different in any of the groups tested in the acute and subchronic toxicity studies. All parameters tested were similar among groups, and the lack of tissue damage was corroborated by the absence of histopathological alterations and relative weight changes in liver [47] [48]. However the routes of exposure studied were not with occupational purpose.

\subsection{Effect of Nanoparticles on Reproductive System}

Ema et al. (2010) performed a review about studies in vivo and in vitro on the reproductive and developmental toxicity of manufactured nanomaterials including metallic and metal oxide-based particles, fullerenes $\left(\mathrm{C}_{60}\right)$, carbon black (CB), and luminescent particles. In vivo studies showed different responses according to the route of administration and the type of nanoparticle. On the other hand, studies in vitro revealed that $\mathrm{TiO}_{2}$ and $\mathrm{CB}$ nanoparticles affected the viability of mouse Leydig cells, that gold nanoparticles reduced the motility of human sperm, that silver, aluminum, and molybdenum trioxide were toxic to mouse spermatogonia stem cells, that silica nanoparticles and $\mathrm{C}_{60}$ inhibited the differentiation of mouse embryonic stem cells and midbrain cells, respectively, and that cadmium selenium-core quantum dots inhibited pre- and postimplantation development of mouse embryos [49]. Changes in gene expression for gonadal development were also observed after exposure to diesel exhaust [50]. 
Few publications about nanoparticle and nanofiber trafficking at the feto-maternal interface in early human pregnancy, however, unless nano-specific biokinetics are properly understood, it will be difficult to ensure identification of potential "nano-thalidomides" among all the newly engineered nanoparticles and fibers, based on the models available in reproductive toxicology, as cited by Juch et al. (2013) [51].

Almost all the studies concerning reproductive toxicity of nanomaterials are conducted with animals or with cell lines and other types of in vitro studies and also alternative methods. Further studies using relevant concentrations closely reflecting expected levels of human exposure are needed, including occupational exposure concentrations and also biomedical administration doses.

The severity factors they used to create the bands requiring increased controlling of exposure included surface chemistry, particle shape, particle diameter, solubility, carcinogenicity, reproductive toxicity, mutagenicity, and dermal hazard potential. While further data are needed and collected for accurate control of exposure to, and assessing risks of ENM, exposure control and risk management approaches such as control banding can be highly valuable [44] [52].

\section{Particle Release and Exposure}

Many studies have yet to be done and confirmed, so in most cases, the reactivity of materials at nanosizes is unknown and the assessment of exposure, too. The nanomaterials may have different health impacts when compared to fine-sized (bulk) particle-types of similar chemical composition. In this regard, the knowledge of physical and chemical properties such as particle size distribution, morphology, particle composition, particle surface area, particle number concentration, surface chemistry, purity, crystalline forms, thermal response, behavior and particle reactivity in solution are particularly important for the purpose of risk assessment [18] [23] [24].

Until more information becomes available on the mechanisms underlying nanoparticle toxicity, it is uncertain as to what measurement technique should be used to monitor exposures in the workplace. Current research indicates that mass and bulk chemistry may be less important than particle size and shape, surface area, and surface chemistry (or activity) for occupational evaluation of nanostructured materials [53]-[55].

As production and applications of nanomaterials expand, potential human exposures will also increase. High concentrations are found near the source (highways) or where NM are manufactured or used for various applications. In an industrial facility, workers often have the risk of being exposed to a number of harmful materials and particles. Among these particles, fine and ultrafine $(<100 \mathrm{~nm})$ are now the cause of most concern [19].

The most critical issue in regard to human health is the release of nanoparticles in the air as aerosols. In aerosol form they are very mobile and can easily be taken into the body through inhalation. Due to NP very small size and unique characteristics, they often have the ability to stay suspended in air for a long time [12]. Particle release is most likely to occur in accidental releases in the manufacturing process, maintenance, cleaning, or non-routine procedures, or after the manufacturing process, once the materials are in the hands of consumers. Old pieces of equipment, liquids used for cleaning, and equipment used for cleaning may accidentally release nanoparticles into the environment unless special care is taken in their traceability and final storage. Additionally, in industrial processes that do not specifically use or create nanomaterials, nano-sized particles can be produced and released during activities like welding, smelting, combustion, as bioaerosols (NIOSH, 2009) and as anthropogenic nanoparticles.

The magnitude of exposure to nanomaterials when working with NP depends on the likelihood of particles for being released from the powders during handling. The following workplace tasks can increase the risk of exposure to nanoparticles: [55] Working with nanomaterials in liquid media without adequate protection (e.g., gloves);

- Working with nanomaterials in liquid during pouring or mixing operations, or where a high degree of agitation is involved;

- Generating nanoparticles in non-enclosed systems;

- Handling (e.g., weighing, blending, spraying) powders of nanomaterials;

- Maintenance on equipment and processes used to produce or fabricate nanomaterials and the cleaning-up of spills and waste material containing nanomaterials;

- Cleaning of dust collection systems used to capture nanoparticles;

- Machining, sanding, drilling, or other mechanical disruptions of materials containing nanoparticles.

The most common way to express occupational exposure is usually by the mass of substance per unit of vo- 
lume of air breathing along with the time of the exposure. When dealing with NP, again, the way in which we measure and regulate may need to be focused on other characteristics of particles to give an accurate picture of dose-response [12]. Current researches indicates that mass and bulk chemistry may be less important than particle size and shape, surface area, and surface chemistry (or activity) for some nanostructured materials [54].

There are many sampling techniques available for measuring airborne nanoaerosols. They can provide useful information for evaluating occupational exposures with respect to particle size, mass, surface area, number concentration, and composition. But, relatively few of these techniques are readily applicable to routine exposure monitoring [32].

Research is underway to develop and improve a system that uses nano-film iron detectors. When acidic nanoparticles deposit on the film, reaction sites are formed for each droplet. These sites can then be scanned to count the number and size of the particles that were deposited [10] [56].

EU-OSHA recommends that measurement technology to determine nanomaterials in the air and on skin have to be developed for routine, workplace application. Focus must be on the further development of person-related measurement technology. At the same time, workplace measurements performed with the currently available measurement technology should be intensified. Particularly in the workplace, differentiation between the ubiquitously occurring ultrafine aerosols and the intentionally produced nanomaterials is required [10]. Research is needed to determine the key physical and chemical characteristics of nanoparticles that determine their hazard potential [54] [55].

\section{Preventative and Control Measures}

In order to limit the occupational exposure of the respiratory tract and the skin, several protective measures like substitution, technical, organizational and personal protection measures could be applied [56]. Until further information on the possible health risks and extent of occupational exposure to nanomaterials becomes available, interim protective measures should be developed and implemented. Given the limited amount of information about health risks that may be associated with nanomaterials, it is prudent to adopt measures to minimize worker exposures.

For most processes and job tasks, the control of airborne exposure to nanoaerosols can be accomplished using a variety of engineering control techniques similar to those used in reducing exposure to general aerosols. The implementation of a risk management program in workplaces where exposure to nanomaterials exists can help to minimize the potential for exposure to nanoparticles.

For this NIOSH (2009) recommends a program including the following elements:

- Evaluating the hazard posed by the nanomaterial based on available physical and chemical property data, toxicology, or health-effects data;

- Assessing the worker's job task to determine the potential for exposure;

- Educating and training workers in the proper handling of nanomaterials (e.g., good work practices);

- Establishing criteria and procedures for installing and evaluating engineering controls (e.g., exhaust ventilation) at locations where exposure to nanomaterials might occur.

- Developing procedures for determining the need for and selecting proper personal protective equipment (e.g., clothing, gloves, respirators);

- Systematically evaluating exposures to ensure that control measures are working properly and that workers are being provided the appropriate personal protective equipment.

Engineering control techniques such as source enclosure (i.e., isolating the generation source from the worker) and local exhaust ventilation systems should be effective for capturing airborne nanoparticles. Current knowledge indicates that a well-designed exhaust ventilation system with a high-efficiency particulate air (HEPA) filter should effectively remove nanomaterials.

The use of good work practices can help to minimize worker exposures to nanomaterials. Examples of good practices include cleaning of work areas using HEPA vacuum pickup and wet wiping methods, preventing the consumption of food or beverages in workplaces where nanomaterials are handled, providing hand-washing facilities, and providing facilities for showering and changing clothes.

No guidelines are currently available on the selection of clothing or other apparel (e.g., gloves) for the prevention of dermal exposure to nanoaerosols. However, some clothing standards incorporate testing with nanometer-sized particles and therefore provide some indication of the effectiveness of protective clothing. 
Respirators may be necessary when engineering and administrative controls do not adequately prevent exposures. Currently, there are no specific limits for airborne exposures to engineered nanoparticles although occupational exposure limits exist for some larger particles of similar chemical composition. It should be recognized that exposure limits recommended for non-nanoscale particles may not be health protective for nanoparticle exposures (e.g., the OSHA Permissible Exposure Limit [PEL] for graphite may not be a safe exposure limit for carbon nanotubes). The decision to use respiratory protection should be based on professional judgment that takes into account toxicity information, exposure measurement data, and the frequency and likelihood of the worker's exposure. While research is continuing, preliminary evidence indicates that NIOSH-certified respirators will be useful for protecting workers from nanoparticle inhalation when properly selected and fit tested as part of a complete respiratory protection program [54] [55].

EPA (2007) made similar recommendations. When producing nanoparticles and nanomaterials, complete physical isolation is the best way to protect employees from exposure. This can be achieved through process modification and local exhaust ventilation. In addition to these engineering controls, good work practices and personal protective equipment may be essential, but less preferable to maintaining a workplace free of hazards and contamination [53].

No guidelines are currently available on the selection of clothing or other apparel (e.g. gloves) for the prevention of dermal exposure to nanoaerosols. However, some clothing standards incorporate testing with nanoscale particles and therefore provide some indication of the effectiveness of protective clothing with regard to nanoparticles. Respirators may be necessary when engineering and administrative controls do not adequately prevent exposures. Currently, there are no specific exposure limits for airborne exposures to engineer [9].

According to ZHAO et al., 2013, the monitoring of nanoparticles has been a challenge to the scientific community, the Advanced Nuclear Analytical Techniques (NATs) are powerful tools for studying a number of basic issues in chemistry and it is an important tool to study the role of nanocompounds and the toxicological aspects. There are some keys challenging issues in nanotoxicology [57].

1) Novel physicochemical properties of nanomaterials (including size, shape, charge, composition, aggregation state and hydrophobicity, etc.);

2) Proper dosimetry and exposure are difficult to accomplish;

3) Cellular uptake, trafficking and exclusion of nanoparticles play key roles in determining their biomedical functions and toxicity;

4) Multiple biological impacts may be exerted by multiple components of nanomaterials;

5) Various interactions of the nanomaterials with biological components, such as proteins and cells, could lead to unique biodistribution, clearance, immune response, and metabolism;

6) Small sizes and low amounts of nanoparticles in target tissues and organs make it difficult to perform quantitative detection and assessment;

7) Differentiation between carbon nanomaterials (such as carbon nanotubes, graphene and fullerene) and carbon-rich biological samples can be obscured due to similarities in composition and dimensions.

\section{Standardization and Regulation}

One potential way of balancing the significant public health benefits of this powerful and promising technology against potential risks may be to look towards the European Union's (EU) comprehensive new chemical regime, Registration, Evaluation, and Authorization of Chemicals (REACH) Regulation. REACH, which is expressly underpinned by the precautionary principle, has shifted the burden of proof about the substance's safety back on to the industry itself. A cornerstone of REACH is that it does not differentiate substances on the basis of "existing" or "new" chemical substances, and requires a manufacturer, importer or producer of a substance to register and complete a technical dossier on all substances over a specified tonnage level before they can have access to the EU market [34].

In conformity with the document "Nanomaterials in REACH" (EC, 2008) within the context of REACH, the main issue pertaining to the development of nanotechnologies and nanomaterials is to ensure their safety to the human health and the environment covering the whole lifecycle. This is a prerequisite for the sustainable use of nanotechnologies and for the success of nanotechnologies in terms of market uptake and societal acceptance. That document alerts that there are no provisions in REACH referring specifically to nanomaterials. However, REACH deals with substances, in whatever size, shape or physical state. Substances at the nanoscale are there- 
fore covered by REACH and its provisions apply to them. It thus follows that under REACH, manufacturers, importers and downstream users have to ensure that their nanomaterials do not adversely affect human health or the environment [58] [59].

This document describes the current state of discussion on how REACH applies to nanomaterials and identifies a number of challenges in the REACH implementation in relation to nanomaterials. The description in this document of how REACH applies to nanomaterials is without prejudice to any future amendment to the legislation that may be deemed appropriate in order to improve and clarify the effective application of REACH to nanomaterials [60].

There some other activities on standardization in development. International Organization for Standardization (ISO), already published 43 standards under the direct responsibility of ISO/TC 229, among them: ISO/TR 27628-Workplace atmospheres. Ultrafine, nanoparticle and nano-structured aerosols; Inhalation exposure characterization and Assessment; ISO/TS 27687 Nanotechnologies. Terminology and definitions for nano-objects. Nanoparticle, nanofibre and nanoplate; ISO/TR 12885-Nanotechnologies. Health and safety practices in occupational settings relevant to nanotechnologies [2] [31] [58] [59].

Some other institutions like ASME (American Society of Mechanical Engineering); ASTM (American Society for Testing and Materials); BSI (British Standards Institution); IEEE (Institute of Electrical and Electronics Engineer) and NIST (National Institute of Standards and Technology) have standards already published or in development. The formation of centers for the testing and standardizing the effects of nanomaterials have been recommended by a large number of concerned researchers and scientists in a broad range of fields [61].

Regarding regulation, there aren't legal guidelines that apply or refer specifically to nanomaterials around the world. But an important adoption happened this year. The European Parliament's environment committee adopted, March 31st 2009, a report by Swedish Green MEP (Manufacturing Extension Partnership), by Carl Schlyter, which calls for tighter controls on nanotechnology, including the application of the "no data, no market" principle contained in the REACH (Registration, Evaluation, Authorization and Restriction of Chemical) substances Directive [58]-[60].

Nowadays, some specialist groups are creating comitees to study nanotoxicology properties of products, one group is known as Nano-Associated Safety Assessment (RT-NASA), that was carried out in six steps: need assessment, physicochemical property, toxicity evaluation, toxicokinetics, peer review, and risk communication of nanocompounds and safety research team. Investigators in part I are responsible for the efficient management and international cooperation in nano-safety studies. Investigators in part II performed the toxicity evaluations of NPs on target organs, and investigators in part III evaluated the toxicokinetics of NPs. This idea indeed to create the best management framework in organizing various research teams and arranging researchers with clear roles, experiments, and expectations and especially in harmonizing and unifying each team to construct a clear outcome [5] [62].

\section{Conclusions}

Nanotechnology offers the promise of unprecedented scientific advancement for many sectors, such as medicine, consumer products, energy, materials, and manufacturing. Nanotechnology has the power not only to improve existing technologies, but also to dramatically enhance the effectiveness of new applications. While nanomaterials present seemingly limitless possibilities, they bring with them new challenges to understanding, predicting, and managing potential safety and health risks to workers [63].

At nanoscale, many materials will exhibit novel properties when compared with their micro or macro-sized equivalents, including, for example, chemical reactivity, strength, mobility and solubility. On the other hand, some of the observed properties of nanomaterials call into question the adequacy of current methods for determining hazard and exposure and for controlling resulting risks [64].

The community strategy on health and safety at work 2002-2006 called on the European Agency for Safety and Health at Work to "set up a risk observatory" to "anticipate new and emerging risks". The publication "Expert Forecast on Emerging Chemical Risks Related to Occupation Safety and Health" (2009) presents the results of the forecast on emerging chemical risks related to occupational safety and health based on an expert survey and a literature review. The risks posed by "nanoparticles and ultrafine particles" are by far the strongest agreed as emerging by the experts.

It recommends that further research should concentrate on the complete life cycle of a given nanomaterial in 
order to identify all exposure situations and the workplaces concerned. In parallel, further research should be undertaken to guarantee the development of "responsible" nanotechnology that integrates health and safety considerations.

In Brazil, the National Council for Scientific and Technological Development (CNPq/MCTI) made an edict in 2011, which aimed to support scientific and technological research projects in the areas of toxicology network and nano instruments, the origin of the formation of networks 6 related to toxicology and two to nano instruments.

Given the lack of current knowledge about the toxicity of nanomaterials and the concern that current safety data sheets do not adequately reflect the hazardous nature of nanomaterials, it is recommended that all nanomaterials should be considered potentially hazardous unless sufficient information to the contrary is obtained.

\section{Acknowledgements}

Authors are grateful to $\mathrm{Pb}$ Brasil magazine for publication support.

\section{References}

[1] NANO - National Nanotechnology Initiative So What Is Nanotechnology? http://www.nano.gov/nanotech-101/what/definition

[2] Schulte, P.A. and Buentello, F.S. (2007) Ethical and Scientific Issues of Nanotechnology in the Workplace. Environmental Health Perspectives, 115, 5-12.

[3] SCENIHR - The Scientific Committee on Emerging and Newly Identified Health Risks, European Commission (2006) What Is Nanotechnology? http://ec.europa.eu/health/opinions2/en/nanotechnologies/1-3/1-introduction.htm

[4] RSC - Royal Society of Chemistry (2009) The Future for Nanoscience and Nanotechnology. http://www.iop.org/activity/policy/Publications/file 22332.pdf

[5] Seong, S.O.O., et al. (2014) Organization of Research Team for Nano-Associated Safety Assessment in Effort to Study Nanotoxicology of Zinc Oxide and Silica Nanoparticles. International Journal Nanomedicine, 9, 3-10.

[6] Lux Research (2008) The Nanotech Report. 4th Edition, Lux, New York, 246 p.

[7] Royal Society and Royal Academy of Engineering (2014) Nanoscience and Nanotechnologies: Opportunities and Uncertainties. RS-RAE, London. http://www.nanotec.or.uk/final/Report.htm

[8] KAS (2009) Are Nano EHS Budgets Too Small? Environmental Health, Occupational Health \& Safety, the Pump Handle. https://thepumphandle.wordpress.com/2009/06/01/are-nano-ehs-budgets-too-small/

[9] Balbus, J.M., Castranova, V., Colvin, V.L., Daston, G.P., Denison, R.A. and Maynard, A.D. (2007) Meeting Report: Hazard Assessment for Nanoparticles-Report from an Interdisciplinary Workshop. Environmental Health Perspectives, 115, 1654-1660.

[10] Cohen, B.S., Li, W., Xiong, J.Q. and Lippmann, M. (2000) Detecting $\mathrm{H}^{+}$in Ultrafine Ambient Aerosol Using Iron Nano-Film Detectors and Scanning Probe Microscopy. Applied Occupational and Environmental Hygiene, 15, 80-89.

[11] Frampton, M.W. (2000) Systemic and Cardiovascular Effects of Airway Injury and Inflammation: Ultrafine Particle Exposure in Humans. Presented at the Workshop in Inhaled Environmental/Occupational Irritants and Allergens: Mechanisms of Cardiovascular and Systemic Responses, Scottsdale, 31 March-2 April, 529-532.

[12] Hamoir, J., Gustin, P., Halloy, D., Nemmar, A., Nemery, B., Vanderplasschen, A., Vincke, G. and Wirth, D. (2003) Effect of Polystyrene Particles on Lung Microvascular Permeability in Isolated Perfused Rabbit Lungs: Role of Size and Surface Properties. Toxicology and Applied Pharmacology, 190, 278-285. http://dx.doi.org/10.1016/s0041-008x(03)00192-3

[13] Kreyling, W.G., Erbe, F., Mayer, P., Oberdörster, G., Semmler, M., Schultz, H. and Takenaka, S. (2002) Translocation of Ultrafine Insoluble Iridium Particles from Lung Epithelium to Extrapulmonary Organs Is Size Dependant but Very Low. Journal of Toxicology and Environmental Health, 65, 1513-1530.

[14] Labhasetwar, V., Sog, C., Humphrey, W., Shebuski, R. and Levy, R.J. (1998) Arterial Uptake of Biodegradable Nanoparticles: Effect of Surface Modifications. Journal of Pharmaceutical Sciences, 87, 1229-1234.

[15] Oberdörster, G., Sharp, Z., Atudorei, V., Elder, A., Gelein, R., Kreyling, W. and Cox, C. (2004) Translocation of Inhaled Ultrafine Particles to the Brain. Inhalation Toxicology, 16, 437-445.

[16] Nel, A. (2005) Air Pollution-Related Illnesses: Effects of Particles. Science, 308, 804-806. http://dx.doi.org/10.1126/science.1108752

[17] Nel, A. (2006) Toxic Potential of Materials at the Nanolevel. Science, 311, 622-627. 
http://dx.doi.org/10.1126/science.1114397

[18] Hussain, S.M., Braydich-Stolle, L.K., Schrand, A.M., Murdock, R.C., Yu, K.O., Mattie, D.M., Schlager, J.J. and Terrones, M. (2009) Toxicity Evaluation for Safe Use of Nanomaterials: Recent Achievements and Technical Challenges. Advanced Materials, 21, 1549-1559. http://dx.doi.org/10.1002/adma.200801395

[19] Borm, P.J.A. (2002) Particle Toxicology: From Coal Mining to Nanotechnology. Inhalation Toxicology, 14, 311-324.

[20] Henneberger, A., Cyrys, J., Couderc, J.P., Ibald-Mulli, A., Rückerl, R. and Wojciech, Z. (2005) Repolarization Changes Induced by Air Pollution in Ischemic Heart Disease Patients. Environmental Health Perspectives, 113, 440 446.

[21] Nemmar, A., Hoylaerts, M.F., Hoet, P.H.M., Dinsdale, D., Smith, T. and Xu, H. (2002) Ultrafine Particles Affect Experimental Thrombosis in an in Vivo Hamster Model. American Journal of Respiratory and Critical Care Medicine, 166, 998-1004.

[22] Oberdörster, G., Oberdörster, E. and Oberdörster, J. (2005) Nanotoxicology: An Emerging Discipline Evolving from Studies of Ultrafine Particles. Environmental Health Perspectives, 113, 823-839.

[23] EU-OSHA - European Agency for Safety and Health at Work (2009) European Risk Observatory Report-Literature Review. http://osha.europa.eu/en/publications/literature reviews/workplace exposure to nanoparticles

[24] EU-OSHA - European Agency for Safety and Health at Work (2009) European Risk Observatory Report-Expert Forecast on Emerging Chemical Risks Related to Occupation Safety and Health. EN 8. http://osha.europa.eu/en/publications/reports/TE3008390ENC chemical risks

[25] Tinkle, S.S., Antonini, J.M., Rich, B.A., Roberts, J.R., Salmen, R. and Depree, K. (2003) Skin as a Route of Exposure and Sensitization in Chronic Beryllium Disease. Environmental Health Perspectives, 111, 1202-1208.

[26] BSI (2005) British Standards, PAS 71. Publicity Available Specification on Vocabulary-Nanoparticle. http://www.bsigroup.com/en/Standards-and-Publications/Industry-Sectors/Nanotechnologies/PAS-71/

[27] Oberdörster, G. (2007) Biokinetics and Effects of Nanoparticles. In: Simeonova, P.P., Opopol, N. and Luster, M.I., Eds., Nanotechnology-Toxicological Issues and Environmental Safety, NATO Science for Peace and Security Series-C, Environmental Security, Springer, Dordrecht, 15-51. http://dx.doi.org/10.1007/978-1-4020-6076-2 2

[28] Chan-Remillard, S., Kapustka, L. and Goudey, S. (2009) Nanotechnology. In: Linkov, I. and Steevens, J., Eds., Nanomaterials: Risks and Benefits, NATO Science for Peace and Security Series-C, Environmental Security, Springer, Dordrecht, 53-66.

[29] Englert, N. (2004) Fine Particles and Human Health-A Review of Epidemiological Studies. Toxicology Letters, 149, 235-242.

[30] Kim, C. and Jaques, P.A. (2004) Analysis of Total Respiratory Deposition of Inhaled Ultrafine Particles in Adult Subjects at Various Breathing Patterns. Aerosol Science and Technology, 38, 525-540.

[31] Shin, J.H., Han, S.G., Kim, J.K., Kim, B.W., Hwang, J.H., Lee, J.S., et al. (2015) 5-Day Repeated Inhalation and 28-Day Post-Exposure Study of Graphene. Nanotoxicology, 20, 1-9. http://dx.doi.org/10.3109/17435390.2014.998306

[32] Chakrabarti, B., Singh, M. and Sioutas, C. (2004) Development of a Near-Continuous Monitor for Measurement of the Sub-150 nm PM Mass Concentration. Aerosol Science and Technology, 38, 239-252.

[33] Warheif, D.B., Laurence, B.R., Reed, K.L., Roach, D.H., Reynolds, G.A.M. and Webb, T.R. (2004) Comparative Pulmonary Toxicity Assessment of Single-Wall Carbon Nanotubes in Rats. Toxicological Sciences, 77, 117-125.

[34] Bowman, D.M. and Calster, V.G. (2008) Reelecting on REACH: Global Implications of the European Union's Chemicals Legislation. Nanotechnology Law and Business. E.C., Brussels. http://ec.europa.eu/environment/chemicals/reach/reach intro.htm

[35] Oberdörster, G., Morrow, P.E. and Spurny, K. (1988) Size Dependent Lymphatic Short Term Clearance of Amosite Fibers in the Lung. The Annals of Occupational Hygiene, 32, 149-156.

[36] Oberdörster, G., Ferin, J. and Lehnert, B.E. (1992) Correlation between Particle Size, in Vivo Particle Persistence, and Lung Injury. Presented at the Workshop on Biopersistance of Respirable Synthetic Fibers and Minerals, Lyon, 7-9 September 1992, 173-179.

[37] Alyaudtin, R.N., Begley, D.J., Kreuter, J., Löbenberg, R., Ramge, P. and Reichel, A. (2001) Interaction of Poly (butylcyanoacrylate) Nanoparticles with the Blood-Brain Barrier in Vivo and in Vitro. Journal of Drug Targeting, 9, 209-221.

[38] Harder, V., Gilmour, P.S., Lentner, B., Karg, E., Takenaka, S. and Ziesenis, A. (2005) Cardiovascular Responses in Unrestrained WKY Rats to Inhaled Ultrafine Carbon Particles. Inhalation Toxicology, 17, 29-42.

[39] Greenemeier, L. (2008) Study Says Carbon Nanotubes as Dangerous as Asbestos. Scientific American. http://www.scientificamerican.com/article.cfm?id=carbon-nanotube-danger 
[40] ASCC-Australian Safety and Compensation Council (2006) A Review of the Potential Occupational Health \& Safety Implications of Nanotechnology. Flinders Consulting Pty Ltd, $77 \mathrm{p}$.

http://www.safeworkaustralia.gov.au/NR/rdonlyres/AC17BA49-8BA1-43B8-BC08-219DE53781E6/0/ASCCReviewO HSImplicationsNanotechnology2006.pdf

[41] Lam, C.W., James, J.T., Mccluskey, R. and Hunter, R.L. (2004) Pulmonary Toxicity of Single-Walled Carbon Nanotubes in Mice 7 and 90 Days after Intratracheal Instillation. Toxicological Sciences, 77, 126-134. http://dx.doi.org/10.1093/toxsci/kfg243

[42] Raloff, J. (2005) Nano Hazards: Exposure to Minute Particles Harms Lungs, Circulatory System. Science News, 167, 179. http://dx.doi.org/10.2307/4015936

[43] Takenaka, S, Karg, E., Kreyling, W.G., Lentner, B., Schultz, H. and Ziesenis, A. (2004) Fate and Toxic Effects of Inhaled Ultrafine Cadmium Oxide Particles in the Rat Lung. Inhalation Toxicology, 16, 83-92. http://dx.doi.org/10.1080/08958370490443141

[44] Maynard, A.D. (2007) Nanotechnology: The Next Big Thing, or Much Ado about Nothing? The Annals of Occupational Hygiene, 51, 1-12. http://dx.doi.org/10.1093/annhyg/mel071

[45] Maynard, A.D. Nanotechnology: Assessing the Risk. http://web.pdx.edu/ pmoeck/phy381/nano\%20risks.pdf

[46] Bulcão, R.P., Freitas, F.A., Venturini, C.G., Dallegrave, E., Durgante, J., Göethel, G., Cerski, C.T.S., Zielinsky, P., Pohlmann, A.R., Guterres, S.S. and Garcia, S.C. (2013) Acute and Subchronic Toxicity Evaluation of Poly(e-caprolactone) Lipid-Core Nanocapsules in Rats. Toxicological Sciences, 132, 162-176. http://dx.doi.org/10.1093/toxsci/kfs334

[47] Bulcão, R.P., Freitas, F.A., Dallegrave, E., Venturini, C.G., Baierle, M., Durgante, J., Sauer, E., Cassini, C., Cerski, C.T.S., Zielinsky, P., Salvador, M., Pohlmann, A.R., Guterres, S.S. and Garcia, S.C. (2014) In Vivo Toxicological Evaluation of Polymeric Nanocapsules after Intradermal Administration. European Journal of Pharmaceutics and Biopharmaceutics, 86, 167-177. http://dx.doi.org/10.1016/j.ejpb.2013.04.001

[48] Bulcão, R.P., Bubols, G.B., Nascimento, S.S., Gauer, B., Sauer, E., Baierle, M., Charão, M.F., Moro, A.M., Brucker, N., Bruinsmann, F.A., Schnorr, C., Moreira, J.C.F., Pohlmann, A.R., Guterres, S.S. and Garcia, S.C. (2015) Do Poly(epsilon-caprolactone) Lipid-Core Nanocapsules Induce Oxidative or Inflammatory Damage after in Vivo Subchronic Treatment? Toxicology Research, No. 4, 994-1005.

[49] Ema, M., Kobayashi, N., Naya, M., Hanai, S. and Nakanishi, J. (2010) Reproductive and Developmental Toxicity Studies of Manufactured Nanomaterials. Reproductive Toxicology, 30, 343-352. http://dx.doi.org/10.1016/j.reprotox.2010.06.002

[50] Ema, M., Naya, M., Horimoto, M. and Kato, H. (2013) Developmental Toxicity of Diesel Exhaust: A Review of Studies in Experimental Animals. Reproductive Toxicology, 42, 1-17. http://dx.doi.org/10.1016/j.reprotox.2013.06.074

[51] Juch, H., Nikitina, L., Debbage, P., Dohr, G. and Gauster, M. (2013) Nanomaterial Interference with Early Human Placenta: Sophisticated Matter Meets Sophisticated Tissues. Reproductive Toxicology, 41, 73-9. http://dx.doi.org/10.1016/j.reprotox.2013.05.011

[52] Savolainen, K., Pylkkanen, L., Norppa, H., Falck, G., Lindberg, H., Tuomi, T., Vippola, M., Alenius, H., Hameri, K., Koivisto, J., Brouwer, D., Mark, D., Bard, D., Berges, M., Jankowska, E., Posniak, M., Farmer, P., Singh, R., Krombach, F., Bihari, P., Kasper, G. and Seipenbusch, M. (2010) Nanotechnologies, Engineered Nanomaterials and Occupational Health and Safety: A Review. Safety Science, 48, 957-963. http://dx.doi.org/10.1016/j.ssci.2010.03.006

[53] EPA (U.S. Environmental Protection Agency) (2008) Nanotechnology. Washington DC. http://www.epa.gov/oppt/nano/stewardship.htm

[54] NIOSH-The National Institute for Occupational Health and Safety (2009) Approaches to Safe Nanotechnology. Managing the Health and Safety Concerns Associated with Engineered Nanomaterials. http://www.cdc.gov/niosh/docs/2009-125/pdfs/2009-125.pdf

[55] NIOSH-The National Institute for Occupational Health and Safety (2008) Nanotechnology at NIOSH. Washington DC. http://www.cdc.gov/niosh/topics/nanotech/

[56] Choi, S.J., Oh, A.J. and Choy, J.H. (2008) Human-Related Application and Nanotoxicology of Inorganic Particles: Complementary Aspects. Journal of Materials Chemistry, 18, 605-712. http://dx.doi.org/10.1039/b711208d

[57] Chen, C., Li, Y.F., Qu, Y., Chai, Z. and Zhao, Y. (2013) Advanced Nuclear Analytical and Related Techniques for the Growing Challenges in Nanotoxicology. Chemical Society Reviews, 42, 8266-8303.

[58] EU-European Commission. Follow-Up to the 6th Meeting of the REACH Competent Authorities for the Implementation of Regulation (EC) 1907/2006 (REACH) 15-16 December 2008. Doc. CA/59/2008 rev. 1. Accessed: 26 June 2009. https://osha.europa.eu/en/legislation/directives/regulation-ec-no-1907-2006-of-the-european-parliament-and-of-the-cou ncil 
[59] EURACTIV (2009) “No Data, No Market” for Nanotechnologies, MEPs Say.

http://www.euractiv.com/innovation-enterprise/data-market-nanotechnologies-mep-news-221588

[60] EU-European Commission (2008) REACH in Brief. E.C., Brussels.

http://ec.europa.eu/environment/chemicals/reach/reach intro.htm

[61] Stern, S.T. and Mcneil, S.E. (2008) Nanotechnology Safety Concerns Revisited. Toxicological Sciences, 101, 4-21. http://toxsci.oxfordjournals.org/cgi/reprint/101/1/4? maxtoshow=\&HITS=\&hits=\&RESULTFORMAT=1\&andorexactti tle $=$ and \& fulltext $=$ nano\&andorexactfulltext $=$ and \&searchid $=1 \&$ sortspec $=$ relevance $\&$ fdate $=/ / \&$ resourcetype $=$ HWCIT http://dx.doi.org/10.1093/toxsci/kfm169

[62] Sequeira, R. (2006) The Nano Enterprise: A Survey of Health and Safety Concerns, Considerations, and Proposed Improvement Strategies to Reduce Potential Adverse Effects. Human Factors and Ergonomics in Manufacturing, 16, 343-368. http://dx.doi.org/10.1002/hfm.20057

[63] Friedrichs, S. and Schulte, J. (2007) Environmental, Health and Safety Aspects of Nanotechnology-Implications for the R\&D in (Small) Companies. Science and Technology of Advanced Materials, 8, 12-18. http://dx.doi.org/10.1016/j.stam.2006.11.020

[64] The Foresight Institute (2005) Preparing for Nanotechnology. Menlo Park. http://www.foresight.org 